\title{
Nationwide 2.5-Year School-Based Public Health Intervention Program Designed to Reduce the Incidence of Caries in Children of Grenada
}

\author{
Mark S. Wolff ${ }^{a}$ Rachel Hill ${ }^{a}$ Maureen Wilson-Genderson ${ }^{b}$ Stuart Hirsch ${ }^{a}$ \\ Ananda P. Dasanayake ${ }^{a}$ \\ a Department of Cariology, New York University College of Dentistry, New York, N.Y., and ${ }^{\text {b } T e m p l e ~ U n i v e r s i t y ~}$ \\ College of Public Health, Philadelphia, Pa., USA
}

\section{Key Words}

Fluoride varnish as a public health intervention - Oral health workforce diversification · Public health intervention

\begin{abstract}
This paper describes an innovative public health intervention, called 'Smile Grenada', targeting the oral health of children in Grenada utilizing the resources of a US dental school, several oral health care companies, local governmental and public health authorities, and Grenadian school personnel. Methods: Preintervention visual/tactile caries examinations were collected from 1,092 schoolchildren (mean age 9.9 years, standard deviation, $S D=3.7$ ) in 2010. The intervention included: (1) classroom-based toothbrushing with fluoridated toothpaste, (2) fluoride varnish applied by trained dental students, teachers and local providers 3 times a year and (3) glass ionomer sealants placed on first permanent molars in children aged 6-8 years. Postintervention data were collected in May, 2013 ( $n=2,301$, mean age 9.8 years, SD =3.7). Decayed and demineralized surfaces were examined for the whole sample and decay/demineralization and sealant retention on 6-year molars were examined separately (ages 6-8 in 2013 cohort). Results: The number of decayed/demineralized surfaces declined across all age groups. The average
\end{abstract}

number of decayed surfaces dropped from 9 at baseline to just over $\sigma\left(F_{1,3,393}=69.8, p<0.0001\right)$ and the average number of demineralized surfaces dropped from 6 to less than 2 (1.8 surfaces; $\left.F_{1,3,393}=819.0, p<0.0001\right)$. For children aged 6-8 years, there were statistically significantly fewer decayed surfaces $\left(t_{1,2,086}=12.40, p<0.0001\right.$; mean baseline 0.93, $\mathrm{SD}=1.75$; mean follow-up $0.23, \mathrm{SD}=0.83$ ) and demineralized surfaces $\left(t_{1,2,086}=19.7, p<0.0001\right.$; mean baseline 2.11, $\mathrm{SD}=2.74$; mean follow-up $0.50, \mathrm{SD}=0.97$ ) on 6-year molars. The Smile Grenada program successfully demonstrated a locally sustainable model for improving oral health in children in a developing country.

(C) 2016 The Author(s)

Published by S. Karger AG, Basel

Oral health status has been a concern of the people and government of Grenada since a survey that was conducted in 1979 [Flanders, 1984]. Subsequent surveys of varying types were conducted in 1984, 1991 and 2000 [Baez, 2001]. These surveys all found extremely high caries rates in children of all ages, with DMFT of 5.2 and 7.22 in 12and 15-year-olds, respectively, which are considered severe by the World Health Organization. Grenada, a sovereign island (132 square miles), is a developing nation in the Southern Caribbean that lies in the south-eastern Ca-

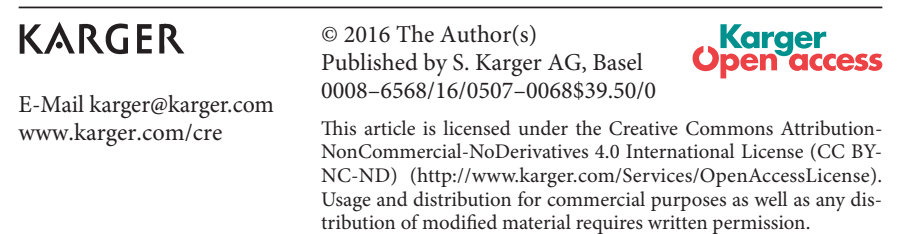


ribbean Sea north-east of Venezuela and is part of the chain of islands called the Grenadines. In 2010, the population was 108,132 , which included 26,000 children. English is the official language. The inhabitants are primarily of African descent. Grenada is the largest island and Carriacou and Petite Martinique are the other major islands that belong to the nation. The island of Grenada is divided into 6 parishes [Government of Grenada Web Portal, 2014]. The dental public health system on the island, staffed by 14 full- and part-time dentists at the time of our initial survey, provides limited dental care (primarily extractions) to the residents of the island through government services. Restorative dental care is available primarily through privately funded care. Multiple oral health surveys have been conducted and multiple proposals for public health dental prevention interventions have been proposed or attempted. Water fluoridation at 2 of the 24 water treatment plants was donated by the Canadian government in the early 1980s but functioned for less than 2 months [Flanders, 1984]. Proposals for salt fluoridation were made but never enacted [Baez, 2001] and a fluoride mouth rinse program was initiated in the early 1980s but not continued [Flanders, 1984]. The Ministries of Health and Education as well as the Chief Dental Surgeon expressed the desire and willingness to support an assessment of oral health of the children of Grenada followed by the implementation of a caries prevention program. The limited budget available for additional oral health care expenditures mandated the development of a program that met several requirements:

1 The implementation of an evidence-based cost-effective caries prevention program that would result in a reduction in caries rates in the permanent dentition for Grenada's 26,000 children

2 An intervention that could be managed locally by the existing workforce (teachers, civil servants and public health professionals)

3 An intervention that could be both sustainable and acceptable to all stakeholders, including children, parents, teachers and governmental agencies

In 2010, the New York University College of Dentistry (NYUCD) undertook this challenge of conducting a comprehensive national oral health survey of children in Grenada. Based on the results of the survey and in consultation with all levels of the government of Grenada, the NYUCD garnered the support from the Colgate Palmolive Company, Henry Schein Cares and GC America to implement a nationwide prevention program to prevent caries in Grenada's 26,000 children. The program was incorporated into Grenada's existing education and early childhood health systems and expanded oral health prevention roles. It included oral hygiene instructions and daily toothbrushing programs in schools utilizing fluoridated toothpaste as well as periodic fluoride varnish and sealant applications. This paper describes the baseline caries survey (completed in January 2010), the details of the resulting preventive program and the results of a follow-up caries survey (completed in May 2013) that evaluated the children's oral health status after a 2.5-year intervention.

It describes the effectiveness of a 2.5-year oral health intervention to reduce childhood caries, which involved the utilization of the existing education and early childhood health systems of the island nation of Grenada, in expanded oral health prevention roles utilizing an open panel repeated-measures study methodology.

\section{Materials and Methods}

\section{Oral Health Survey Sample Development}

To develop a representative dental health survey of the island nation of Grenada, a modified methodology of the World Health Organization Basic Oral Health Pathfinder Survey was utilized to collect baseline and follow-up data using an open panel design. Changes in the Pathfinder recommended ages were made so that children ages 6, 7-8 and 14-15 years were examined for dental caries, as described below, to allow comparative discussion with prior studies [World Health Organization, 1997]. In collaboration with the Grenada Ministries of Education and Health, investigators selected schools for the baseline assessment based upon their enrollment numbers and geographic location, following the Pan American Health Organization recommendations and prior study design [World Health Organization, 1997], to represent students from urban, suburban and rural environments. Oral health examinations were conducted in each of Grenada's 6 parishes and on the island of Carriacou. At the baseline examination each of the locations selected had a minimum of 50 children (approx. 25 females and 25 males) in each age group. In St. George's (the nation's capital and most populous city) the target sample was to be 100 children (50 females and 50 males) in each age group, as recommended in the World Health Organization Pathfinder Survey guidelines for sampling in major cities [World Health Organization, 1997]. Investigators planned baseline examinations of 1,000 children and follow-up examinations of 2,000 children proportionally distributed throughout the parishes.

\section{Recruitment}

In the baseline survey, subjects were solicited for participation through the distribution of a consent form (approved by the Institutional Review Boards at St. George's University and New York University Langone Medical Center - NYULMC), which was brought home by students and completed by parents/guardians. Written parental consent was obtained for all students who took part in the baseline survey. A written assent form was also obtained from students aged 7-8 and 14-15 years during the ini- 
tial assessment in 2010. The principals and the teachers sent the forms home for parents/guardians to sign and return. In addition, the school principals arranged for parent meetings to have questions answered by a representative of the study team. The time and manpower consumption of this process limited the number of examinations possible. During the follow-up examinations in May 2013, no consent/assent forms were utilized (as per exempt status granted by the Institutional Review Board of the NYULMC) as this was a national health survey conducted for the government of Grenada enabling an even broader examination of the children of the nation. The Ministers of Health and Education in Grenada authorized the survey and the school administrators and teachers generously supported the survey, together with the parents.

\section{Exclusion Criteria}

Children who had medical or physical conditions that made the oral examination either impossible or unsafe were excluded, as well as those children who required premedication prior to dental examinations. Children who needed emergency care were referred to the nearest public health dentist and were excluded from the present sample.

\section{Caries Prevention Intervention}

Program Description

Smile Grenada was an intervention designed to fill a large gap in the capacity of dental care providers ( 12 general dentists) to deliver the needed oral health care by focusing on preventive oral health care services with an expanded workforce. The most salient aspects of the program are the inclusion of additional workforce providers, including teachers and dental health auxiliaries, socially responsible international corporations (Colgate Palmolive, Henry Schein Cares, GC America and Columbia Dentoform) and a collaboration between a university with a vision to improve health globally (NYUCD) and a government committed to the oral health of its children (Grenada Ministries of Health and Education). These groups came together to implement a preventive oral health program that was delivered to all 26,000 school-aged children living in Grenada, Carriacou and Petite Martinique.

\section{Procedures}

Between September 2010 and February 2013, the Smile Grenada teams delivered preventive dental care with three components. First, a daily, 2-min toothbrushing routine using fluoridated (approx. 1,000 ppm) toothpaste was implemented in every classroom. The teachers were trained to lead the daily brushing session. The toothbrushes and toothpaste were to remain in the classroom and not to be taken home until the end of the year. The teachers were asked to maintain a log confirming that they conducted the toothbrushing session each day. Second, fluoride varnish (Colgate ${ }^{\circledR}$ PreviDent ${ }^{\circledR}$ Varnish, single-unit dose of $1 \mathrm{ml}$ of this suspension containing $50 \mathrm{mg}$ sodium fluoride equivalent to $22.8 \mathrm{mg}$ fluoride) was applied to each child's teeth utilizing a noncontamination, no-touch technique 3-4 times per year. After the first year, the NYUCD trained local providers and teachers to perform the fluoride varnish applications and assisted with subsequent applications while delivering program supplies. Third, glass ionomer sealants were applied to the first permanent molars of all 6- to 8 -year-olds by teams of NYUCD dental students and local providers using cotton roll isolation and gauze to dry the teeth prior to sealant application. GC Fuji TRIAGE ${ }^{\circledR}$ was selected because of its color, speed of set and ease of use. Difficulties in retention required modification of the placement technique (discussed later). A summary of the preventive procedures performed is included in figure 1. Teacher training included guidance on proper toothbrushing techniques and fluoride varnish application (which took less than 1 min per application to create minimal disruption to the classroom), as well as age-appropriate lessons for classroom-based oral health and nutrition education. Emphasis on teacher training was crucial for program sustainability and longevity.

\section{Measures}

Fluoride in Water Supply

Fluoride concentration of community water supplies was determined by the collection of a total of 18 water specimens $(50 \mathrm{ml})$ from taps throughout Grenada and Carriacou during baseline data collection. Fluoride levels were assessed by an ion-selective electrode method utilizing a fluoride ion-specific electrode (Orion 9609) connected to an ion analyzer, Orion $720 \mathrm{~A}$ (Orion Research Inc., Boston, Mass., USA). Calibration of the ion-specific electrode and analyzer was carried out utilizing standard fluoride solutions in triplicate. Validation of the analyses was done using internal standards and a coefficient of variation lower than 5\% was considered acceptable. Data were recorded for each specimen and repeated after separate calibration curves on the electrode to confirm all results. Data are reported as fluoride concentration per milligram/liter and compared to the therapeutic benchmark level of $0.7 \mathrm{mg} / \mathrm{l}$.

\section{Self-Reported Dental Care}

At the time of dental examination the children were, by selfreport, asked whether they brushed their teeth, how often they brushed their teeth, what substance was used on the toothbrush/ how many times each day and when they had last visited a dentist.

\section{Intervention Indicators}

The intervention was assessed via the following indicators before and after the intervention: the rate of toothbrushing in the classrooms, fluoride varnish placement and the presence of sealants.

\section{Clinical Examination}

Examinations were conducted by 5 teams of examiners/recorders at baseline and 6 teams at follow-up. The baseline examinations were completed over a 2-week period in January 2010 and the follow-up examination was conducted over 1 week in May 2013. All examinations were conducted utilizing infection control standards for field examinations, using disposable products and surface disinfection. All examination information was recorded and data verified at the time of the examination. Each child was examined to determine the number of decayed, demineralized, missing and/or filled surfaces of teeth. A visual/tactile examination of teeth was conducted utilizing a dull explorer in a noncompressive mode, a mirror, bright light and compressed air to dry the teeth where needed. All teeth present were recorded. All tooth surfaces were charted for the presence of decay (defined as cavitation visible to the dentin) and demineralization (defined as loss of enamel ranging from white frosty enamel to loss of enamel surface integrity not penetrating to the dentin), as well as for missing (as judged by ageappropriate presence/absence and history where possible) or filled 
2009

January 2009

Site visit and meetings with the Ministry of Health

2011

January 2011

Workshop/training for 15 local providers
February 2011

Distribute toothbrushes and toothpaste

Initiate daily in-class

toothbrushing program

Initiate school-based fluoride

varnish program
2010

January 2010

Conduct initial Grenada National Oral Health Survey
2012

February 2012

Maintain school-based

toothbrushing, fluoride and

sealant programs

Begin training teachers to

apply fluoride varnish
May 2012

Maintain school-based

toothbrushing, fluoride and

sealant programs

Continue teacher trainings

Conduct PTA education

sessions
April 2011

Initiate sealant program

Continue school-based

toothbrushing and fluoride

programs

Conduct PTA education

sessions
September 2011

Distribute toothbrushes and toothpaste

Continue school-based toothbrushing, fluoride and

sealant programs

Conduct PTA education sessions

September 2012

Distribute toothbrushes and

toothpaste

Continue school-based

toothbrushing, fluoride and

sealant programs

Transition fluoride program to

teachers

Conduct PTA education sessions

2013

February 2013

Maintain school-based

toothbrushing and follow-up

on fluoride program
May 2013

Nationwide Oral Health Survey

and transition Smile Grenada to

Ministry of Health

Fig. 1. A summary of the preventive procedures performed.

teeth (as determined by visual/tactile examination). Examiner/recorder teams were calibrated to agreement with a reference examiner prior to the initiation of the survey examinations and duplicate examinations were conducted to confirm interrater reliability for caries diagnosis. Baseline interrater variability between the gold standard examiner (M.S.W.) and each examiner for the presence or absence of cavitation yielded percent agreement values over $84 \%$ for 3 of the 5 examiners. The 2 who received lower percent agreement values were retrained until over $70 \%$ agreement was reached. Intrarater variability yielded kappa values over $74 \%$. Postintervention interrater variability between the gold standard examiner (M.S.W.) and each examiner yielded percent agreement values over $86 \%$ for 5 of the 6 examiners. The examiner who received the lower percent agreement values was retrained until over $70 \%$ agreement was achieved. Intrarater variability yielded percent agreement values over $80 \%$.

\section{Data Analysis}

Context of the Intervention

Water fluoridation findings for the water collected throughout the island are presented as the backdrop for the current status of the public health-related dental infrastructure support. Likewise, characteristics of the child sample and the child self-reported experience with dental care provides a context for the intervention at the individual level.

Grenada Caries Survey: Results of a 2.5-

Year Prevention Program
Intervention Indicators

Compliance with toothbrushing in the classrooms, successful fluoride varnish application and the presence of sealants are reported for each target age group.

\section{Clinical Examination}

Each tooth was classified as missing age-appropriate, present or missing not age-appropriate; present teeth were classified as primary or permanent. Each surface for each present tooth was coded as decayed, filled, demineralized, partially sealed, sealed or intact. Individual surfaces were aggregated to create whole mouth totals for decayed, filled, demineralized, partially sealed, sealed or intact teeth, with a separate code for missing teeth not age-appropriate. Aggregate totals were also created separately for primary teeth, permanent teeth and the first permanent molars.

Descriptive statistics including the mean and standard deviation for each clinical indicator were computed. A general linear model (GLM) was used to evaluate mean differences in decayed and demineralized surfaces for pre-post intervention, by age and for age and pre-post intervention combined. GLM is analogous to ANOVA but corrects for unbalanced numbers in the different groups being compared (e.g. 2010 vs. 2013). 
Table 1. Age distribution of the students for the 2010 preintervention and the 2013 postintervention clinical assessments

\begin{tabular}{lll}
\hline Age, years & $\begin{array}{l}2010, \\
\mathrm{n}(\%)\end{array}$ & $\begin{array}{l}2013, \\
\mathrm{n}(\%)\end{array}$ \\
\hline 6 & $259(23.7)$ & $508(22.1)$ \\
7 & $220(20.2)$ & $449(19.5)$ \\
8 & $172(15.8)$ & $478(20.8)$ \\
14 & $289(26.5)$ & $507(22.0)$ \\
15 & $151(13.8)$ & $360(15.6)$ \\
\hline Total & 1,091 & 2,301 \\
\hline
\end{tabular}

Table 2. Dental utilization characteristics of the children of Grenada at baseline

\begin{tabular}{lrr}
\hline Variable & $\mathrm{n}$ & $\%$ \\
\hline Toothbrush use & & \\
$\quad$ No & 44 & 4.0 \\
$\quad$ Yes & 1,030 & 94.5 \\
$\quad$ Shared & 16 & 1.5 \\
\hline Toothpaste use & 13 & \\
$\quad$ No & 1,023 & 1.2 \\
Yes & 54 & 53.9 \\
Other & & 5 \\
\hline Brushing frequency & 263 & 24.1 \\
1 & 653 & 59.9 \\
2 & 151 & 13.9 \\
3 & 23 & 2.1 \\
$>4$ & & \\
\hline Last dental visit & 794 & 72.8 \\
Never & 19 & 1.7 \\
$<12$ months & 193 & 17.7 \\
$12-24$ months & 81 & 7.4 \\
$>24$ months & &
\end{tabular}

Table 3. Cumulative school visits and interventions island-wide Smile Grenada program

Total counts

School-wide fluoride application sessions

(81 primary and secondary schools island-wide) $\quad 729$

Toothbrushes/toothpastes distributed 69,562

Fluoride varnish applications $\quad 117,211$

Number of student sealant visits ${ }^{1} \quad 24,132$

Number of sealants applied $\quad 69,444$

PTA meetings attended

21

Public health nurse training

13

${ }^{1}$ Multiple students received sealants multiple times.

\section{Results}

\section{Water Fluoridation}

Water fluoridation levels of the 18 water samples collected from throughout the island revealed fluoride concentration that ranged between 0.00 and $0.060 \mathrm{mg} / \mathrm{l}$. None of the specimens reached the level of $0.7 \mathrm{mg} / \mathrm{l} \mathrm{con-}$ sidered ideally therapeutic.

\section{Sample Description}

Investigators examined a total of 1,091 and 2,301 children at baseline and after intervention, respectively, from the 6 parishes on Grenada and the island of Carriacou. The number of children per parish ranged from 34 in the smallest parish to 255 in the largest. Table 1 presents the age distribution of the students for the 2010 preintervention and the 2013 postintervention clinical assessments. The goal to have an even representation of students from the targeted age groups was successful.

\section{Child Self-Reported Dental Care}

Interviews of nearly 1,000 children participating in the clinical survey at the start of the dental health evaluation revealed only a small percentage of children who never brushed (4\%), virtually all claiming to utilize toothpaste (94\%) and those who brushed their teeth claiming to brush regularly at least once per day (95\%). Seventy-three percent of the children being examined had never seen a dentist (table 2).

\section{Intervention Assessment}

Table 3 contains the cumulative data for the number of treatments provided during Smile Grenada. The indicators varied by age level of the students.

\section{Brushing}

The primary school classrooms had nearly $100 \%$ compliance with the brushing program. Nearly $80 \%$ of the preschool classrooms participated in the toothbrushing program. The toothbrushing program had minimal success in the secondary schools, as the older students did not wish to comply in school.

\section{Varnish}

Fluoride varnish application in the primary schools was administered 3 times per year for nearly $100 \%$ of the children. The varnish application occurred at $<25 \%$ of the preschools with an irregular interval and in the secondary schools the varnish application occurred with approximately $15 \%$ of the students participating as 
Table 4. Pre- and postintervention clinical indicators by age and total sample

\begin{tabular}{|c|c|c|c|c|c|c|}
\hline & $\begin{array}{l}\text { all } \\
(\mathrm{n}=1,091)\end{array}$ & $\begin{array}{l}\text { age } 6-8 \\
(n=652)\end{array}$ & $\begin{array}{l}\text { age } 14-15 \\
(\mathrm{n}=439)\end{array}$ & $\begin{array}{l}\text { all } \\
(\mathrm{n}=2,301)\end{array}$ & $\begin{array}{l}\text { age } 6-8 \\
(n=1,435)\end{array}$ & $\begin{array}{l}\text { age } 14-15 \\
(\mathrm{n}=867)\end{array}$ \\
\hline Total teeth & $24.43 \pm 3.2$ & $22.22 \pm 2.05$ & $27.70 \pm 1.09$ & $24.48 \pm 2.97$ & $22.5 \pm 1.72$ & $27.76 \pm 1.11$ \\
\hline Total permanent teeth & $16.77 \pm 9.48$ & $9.44 \pm 3.99$ & $27.64 \pm 1.20$ & $16.48 \pm 9.27$ & $9.69 \pm 3.78$ & $27.72 \pm 1.16$ \\
\hline Total primary teeth & $7.66 \pm 6.72$ & $12.78 \pm 3.21$ & $0.07 \pm 0.39$ & $8.00 \pm 6.75$ & $12.81 \pm 3.41$ & $0.04 \pm 0.26$ \\
\hline Total permanent decayed surfaces & $3.26 \pm 5.56$ & $1 \pm 1.86$ & $6.55 \pm 7.25$ & $1.58 \pm 3.81$ & $0.26 \pm 0.93$ & $3.73 \pm 5.42$ \\
\hline Total filled teeth & $0.24 \pm 1.15$ & $0.12 \pm 0.76$ & $0.41 \pm 1.55$ & $0.29 \pm 1.16$ & $0.15 \pm 0.73$ & $0.52 \pm 1.61$ \\
\hline Total primary filled teeth & $0.05 \pm 0.49$ & $0.09 \pm 0.63$ & $0 \pm 0.00$ & $0.08 \pm 0.55$ & $0.13 \pm 0.69$ & $0 \pm 0.03$ \\
\hline Total permanent filled teeth & $0.19 \pm 1.04$ & $0.03 \pm 0.38$ & $0.41 \pm 1.55$ & $0.20 \pm 1.03$ & $0.02 \pm 0.15$ & $0.51 \pm 1.61$ \\
\hline Missing not age-appropriate & $1.73 \pm 1.2$ & $1.94 \pm 1.35$ & $1.44 \pm 0.86$ & $1.69 \pm 1.11$ & $1.89 \pm 1.28$ & $1.37 \pm 0.69$ \\
\hline Total permanent demineralized & $4.44 \pm 5.82$ & $2.57 \pm 3.56$ & $7.22 \pm 7.24$ & $1.32 \pm 2.14$ & $0.53 \pm 1.01$ & $2.63 \pm 2.78$ \\
\hline Total partial sealed & $0 \pm 0.00$ & $0 \pm 0.00$ & $0 \pm 0.00$ & $0.71 \pm 1.11$ & $1.12 \pm 1.23$ & $0.01 \pm 0.12$ \\
\hline Total primary partial sealed & $0 \pm 0.00$ & $0 \pm 0.00$ & $0 \pm 0.00$ & $0 \pm 0.00$ & $0 \pm 0.00$ & $0 \pm 0.00$ \\
\hline Total permanent sealed & $0 \pm 0.00$ & $0 \pm 0.00$ & $0 \pm 0.00$ & $0.71 \pm 1.11$ & $1.12 \pm 1.23$ & $0.01 \pm 0.12$ \\
\hline Total sealed & $0 \pm 0.00$ & $0 \pm 0.00$ & $0 \pm 0.00$ & $0.09 \pm 0.38$ & $0.14 \pm 0.47$ & $0.01 \pm 0.12$ \\
\hline Total primary sealed & $0 \pm 0.00$ & $0 \pm 0.00$ & $0 \pm 0.00$ & $0 \pm 0.00$ & $0 \pm 0.00$ & $0 \pm 0.00$ \\
\hline Total permanent sealed & $0 \pm 0.00$ & $0 \pm 0.00$ & $0 \pm 0.00$ & $0.09 \pm 0.38$ & $0.14 \pm 0.47$ & $0.01 \pm 0.12$ \\
\hline
\end{tabular}

Values are means \pm SD.

many students refused to participate. There were no reported complaints or adverse events associated with the trained lay teachers and assistants placing the fluoride varnish.

\section{Sealant}

The placement of the glass ionomer sealants on the first molars of all 6- to 8-year-olds proved most challenging. The sealants were place by teams of NYUCD dental students and local providers utilizing cotton roll isolation. At the first attempt, glass ionomer sealants were placed without an etching of the surface and very low retention rates were found at the 4-month follow-up varnish visit $(<5 \%)$. Glass ionomer sealants were reapplied to the same children/teeth at each of the follow-up varnish visits utilizing slightly different placement techniques and $100 \%$ follow-up quality assurance measures to try to improve the retention rates. The overall retention rates remained poor ( $<10 \%$ at 4 months) regardless of the technique utilized.

\section{Clinical Indicators}

The descriptive statistics for the clinical indicators for the pre-and postintervention periods for the younger and older students as well as for the overall samples are presented in table 4.

\section{Decay}

The GLM comparing decayed surfaces before and after the intervention revealed significant reductions in total decayed surfaces $\left(\mathrm{F}_{3,3,390}=78.66, \mathrm{p}<0.0001\right)$, primary decayed surfaces $\left(\mathrm{F}_{3,3,390}=19.84, \mathrm{p}<0.0001\right)$ and permanent decayed surfaces $\left(\mathrm{F}_{3,3,390}=113.77, \mathrm{p}<0.0001\right)$. These models included age and revealed that the reductions in total decayed surfaces were significant for both the younger and the older age groups $\left(\mathrm{F}_{3,3,390}=166.93\right.$, $\mathrm{p}<0.0001$; fig. 2). The reductions in primary decay were significant for the younger children and the reductions in permanent decay were significant for the older children. 
Fig. 2. Decayed and demineralized surfaces per child, 2010 vs. 2013 ( $p<0.0001$ ). a Total surfaces. b Primary surfaces. c Permanent surfaces.

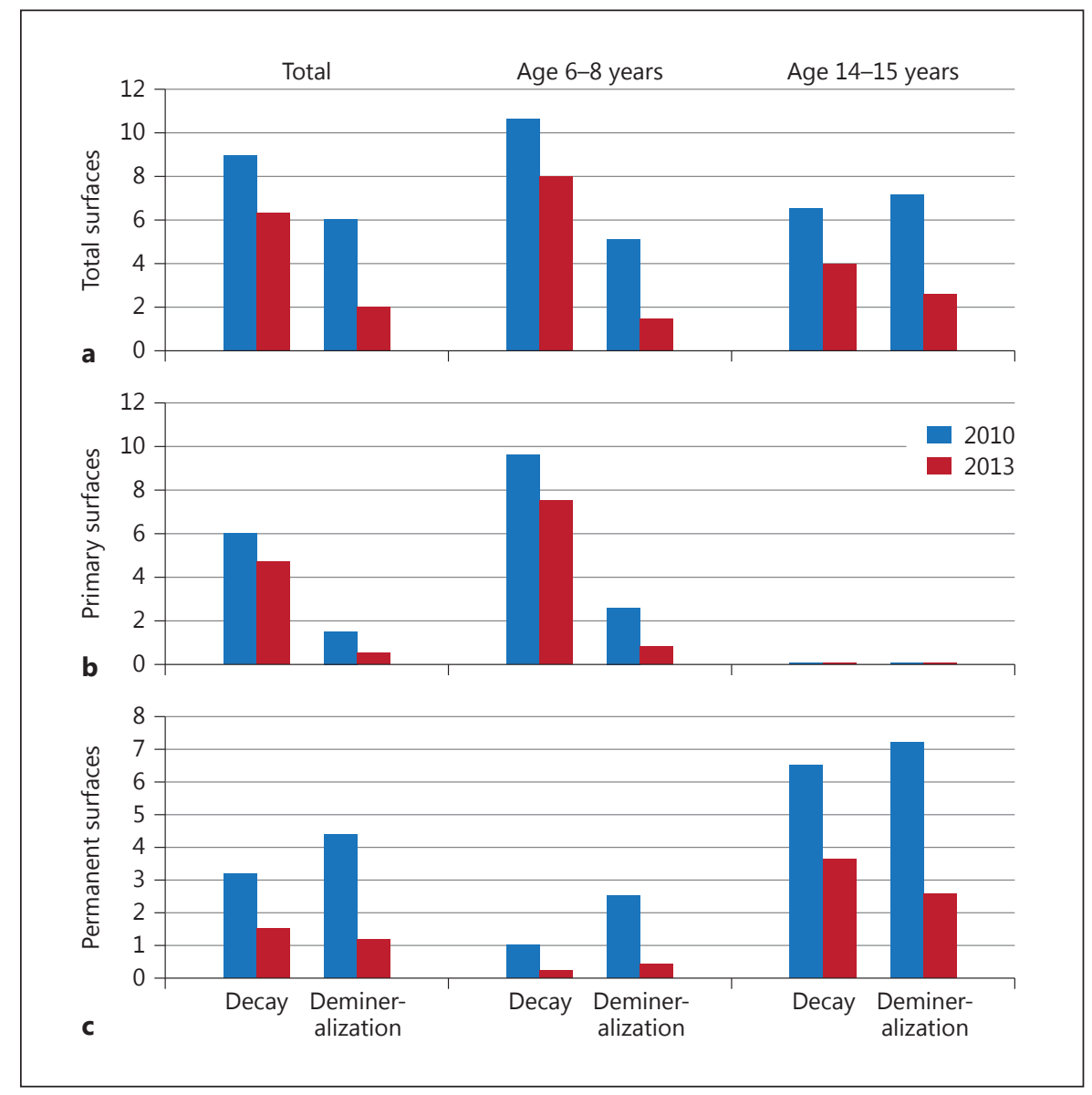

Demineralization

The GLM comparing demineralized surfaces before and after the intervention revealed significant reductions in total demineralized surfaces $\left(\mathrm{F}_{3,3,390}=793.01, \mathrm{p}<\right.$ $0.0001)$, primary demineralized surfaces $\left(\mathrm{F}_{3,3,390}=288.53\right.$, $\mathrm{p}<0.0001)$ and permanent demineralized surfaces $\left(\mathrm{F}_{3,3,390}=573.96, \mathrm{p}<0.0001\right)$. These models included age and revealed that the reductions in total demineralized surfaces were significant for both the younger and the older age groups $\left(\mathrm{F}_{3,3,390}=119.59, \mathrm{p}<0.0001\right.$; fig. 2$)$. The reductions in primary demineralization were significant for the younger children, while the reductions in permanent demineralization were significant for the older children.

As can be noted in table 5, there was a $75 \%$ reduction in the number of new cavitations and new demineralizations developed in the first molars during this 2.5-year study. Very few sealants were observed at either the first return visit for fluoride application or after repeated sealant applications (table 5).

\section{Discussion}

Smile Grenada had a dramatic impact on the clinically measurable indicators of oral health for school-aged children in Grenada. There were no other changes in policy or health interventions that occurred between 2010 and 2013 that may have contributed to the findings and changes in the recruitment technique (no consent) added schools to the examinations, thereby reducing the chance that the screening examinations changed awareness or behaviors. Its success relied on the cooperation of teachers, dental health auxiliaries, socially responsible international corporations (Colgate Palmolive, Henry Schein Cares, GC America and Columbia Dentoform) and the government of Grenada, as well as the leadership and direct involvement of the NYUCD. Together, we implemented a preventive oral health program, which has had a dramatic impact on the clinically measurable indicators of oral health for the school-aged children in Grenada. These results highlight the importance of interprofes- 
Table 5. Analysis of 6-year molars: caries/demineralized/missing/sealant/partially sealed surfaces

\begin{tabular}{lllll}
\hline & $\begin{array}{l}2010 \\
\text { age 6-8 }\end{array}$ & $\begin{array}{l}2010 \\
\text { age 14-15 }\end{array}$ & $\begin{array}{l}2013 \\
\text { age 6-8 }\end{array}$ & $\begin{array}{l}2013 \\
\text { age 14-15 }\end{array}$ \\
\hline Decayed surfaces & $1.02 \pm 1.81^{*}$ & $2.91 \pm 3.13$ & $0.25 \pm 0.86^{*}$ & $1.91 \pm 2.85$ \\
Demineralized surfaces & $2.11 \pm 2.74^{*}$ & $1.98 \pm 2.31$ & $0.50 \pm 0.97^{*}$ & $1.09 \pm 1.44$ \\
First molars missing & & $1.16 \pm 0.37$ & & $1.33 \pm 0.65$ \\
Intact sealant & & & $0.14 \pm 0.47$ & $0.01 \pm 0.12$ \\
Partially retained sealant & & & $1.12 \pm 1.23$ & $0.01 \pm 0.12$ \\
\hline
\end{tabular}

Values are means $\pm \mathrm{SD}{ }^{*} \mathrm{p}<0.0001$

sional involvement in creating health promotion interventions.

When looking to develop a caries prevention strategy for large regions, underserved communities or even small nations, it is as important to build on the infrastructural strengths of the community as it is to understand the current limitations of the health care/dental care systems. Grenada has a very significant primary health care system, though it has weakness in its dental infrastructure (12-14 dentists per 110,000 population). Grenada boasts a national adult literacy rate of $96 \%$ and despite often difficult access to schools $90 \%$ of children enroll and 33-50\% attend prekindergarten education [World Health Organization, 2007]. This infrastructure makes an educationbased program likely to be effective but, as in most environments, resources to increase health care expenditures are highly limited.

One of the most cost-effective caries prevention programs, requiring the least cooperation to assure compliance, is fluoridation of the public water supply [Newbrun, 1989; Brunelle and Carlos, 1990; Armfield, 2010; RuggGunn and Do, 2012; Johnson et al., 2014]. In Grenada, this had been pilot tested in 2 out of 24 (now 29) locations and the fluoridation units were not maintained [Flanders, 1984]. Fluoridation of the public water supply in Grenada would require significant investment in the fluoridation equipment and substantial manpower investment in public works staff and materials to maintain the facilities. It was an impractical solution for Grenada.

Salt fluoridation, first utilized nationwide in Switzerland, was first proposed for Grenada nearly 25 years earlier as it had shown significant reductions in dental caries in countries such as Mexico, Uruguay, Costa Rica and Jamaica [Estupiñán-Day, 2005]. No progress has been made to institute a salt fluoridation program in Grenada.

Grenada Caries Survey: Results of a 2.5-

Year Prevention Program
Caries is found an estimated $62 \%$ of the time on the occlusal surfaces on permanent molars with caries [Brown et al., 2000]. The use of dental sealants is a well-proven measure for the prevention of pit and fissure caries and has been found to be effective in school-based programs [Ahovuo-Saloranta et al., 2008; Gooch et al., 2009]. In fact, sealing noncavitated caries has been demonstrated to be effective in managing these lesions for years [Griffin et al., 2008]. Glass ionomer sealants are hydrophilic, considered moisture friendly and have the promise of reducing caries (possibly through passive fluoride release) even when partially retained [Mejare and Mjor, 1990; Antonson et al., 2006]. Unfortunately, glass ionomer sealant retention has been reported to be poor [Smales and Wong, 1999; Poulsen et al., 2001]. In this intervention, we selected the use of GC Fuji TRIAGE ${ }^{\circledR}$ self-hardening glass ionomer as a sealant in the desire to find a suitable material with a simple application technique that could be successfully placed by a minimally trained lay person because of the limited number of dentists on the island. Unfortunately, the material was sensitive to heat, setting rapidly. Despite working as teams of an assistant (to keep the surface uncontaminated by saliva) and provider (to place the sealant), very few sealants were observed at the first return visit for fluoride application. The sealant application technique was repeatedly modified, including quality assurance steps after placement, yet the retention for follow-up as short as 1 week proved poor. Many children had all 4 sealants replaced as many as 6 times over the 2.5 -year program. The sealant process was the most expensive and time-consuming process in the Smile Grenada program. It was the least transferrable to a lay provider and due to very short retention, probably had very little clinical effect (table 5). This study found decreases in caries in both the pit and fissure system and smooth surfaces. Though impossible to state definitively, the ex- 
tremely short retention (frequently less than $24 \mathrm{~h}$ ) of the sealants is not expected to contribute significantly to the decrease in caries. A recent Cochrane Review by Hiiri et al. [2010] reported significant caries reduction from frequent fluoride varnish application consistent with that seen here and recommended additional study to determine whether there is a benefit of fluoride varnish and sealant application versus fluoride varnish alone [Hiiri et al., 2010]. At this time, we believe that the utilization of sealants is too expensive and too unreliable to recommend for broad-based school-based caries prevention.

Other caries reduction programs have demonstrated that utilizing proper home care, including supervised toothbrushing with a fluoride-containing toothpaste, successfully lowers caries rates [Twetman et al., 2003]. In addition, fluoride varnish programs with 2-4 applications annually have successfully demonstrated reduced caries rates without changing any other home care practices [Weintraub et al., 2006; Marinho et al., 2013]. Some studies question the use of fluoride varnish as a public health measure, especially when combined with supervised toothbrushing, but these studies involved subjects with baseline DMFS/dmfs levels that were less than half the caries rate seen in the children of Grenada [Milsom et al., 2011; Agouropoulos et al., 2014].

With caries frequency found to be quite high and dental service utilization reported to be quite low, it was clear that both home brushing and dental office-mediated solutions were not feasible. By selecting the schools and utilizing teachers as part of the oral health prevention workforce, the program proposed could achieve better access and outcomes with the children at minimal loss of educational curricular time and minimal increase in the country's annual health care expenditure. In addition, this preventive program would only minimally change the burden on the current dental health care providers. A survey of teachers at the conclusion of the intervention revealed that the oral health program was extremely well accepted. The teachers' reactions to the classroom-based nature of Smile Grenada activities was extremely positive $-71.9 \%$ of the teachers believed the 2 -min toothbrushing routine was not disruptive, $82.7 \%$ did not feel applying fluoride varnish once every 3 months took up too much class time and $77.6 \%$ did not feel that applying fluoride varnish to the students' teeth would be a problem for them to continue. Even with a relatively simple training program, the teachers were able to instruct in toothbrushing technique, toothpaste usage and fluoride application. There were no adverse events reported other than toothbrushes growing mold over long breaks when stored in hot damp places for weeks at a time. This issue was alleviated by replacing the toothbrushes, providing teachers and parents with instructions for how to clean toothbrushes, and having students store toothbrushes open to the air, allowing them to thoroughly dry. There were no reported complaints or adverse events associated with trained lay teachers and assistants placing the fluoride varnish. The varnish was placed safely and was seen to be effective. A measure of the effectiveness of this program is to determine the decay/demineralization rates in newly erupted first molars that had erupted during this program and compare the decay/demineralization values found in the baseline examinations. As can be noted in table 5, there was a $75 \%$ reduction in the number of new cavitations and new demineralizations developed in the first molars during this 2.5-year study. This confirms the generally held belief that in high caries risk environments where the infrastructure improvements of public water supply may not be possible, school-based, public interventions implemented by a nontraditional lay workforce can result in significant oral health improvements

\section{Conclusion}

The results of the pre- and post-caries surveys indicated a reduction in caries incidence and that schoolbased anticaries public health measures conducted primarily by teachers can be safely administered and highly effective in reducing dental caries. Unfortunately a high volume, less labor-intensive sealant technique could not be effectively achieved when sealant retention was utilized as an outcome measure. An additional benefit of this nationwide program was increasing the awareness of good oral health among children, teachers, parents and local health care providers. By training the teachers and the local providers, we may have added sustainability, which can be tested in a subsequent study. It is important to point out the barriers to the widespread implementation of this type of program. Active participation of multiple segments of local governments, such as the Ministries of Health and Education, may be a challenge. Getting the school principals, teachers and parents to buy into the program is another challenge given the busy schedules within schools. Communities with minimal access to preventive health care and lack of community fluoridation and other preventive services are best suited for similar programs. As long as the local officials and dental boards do not object, there will be no legal implications to the use of nondentally trained staff to deliver fluoride varnishes.
76

Caries Res 2016;50(suppl 1):68-77 DOI: $10.1159 / 000439058$
Wolff/Hill/Wilson-Genderson/Hirsch/ Dasanayake 
This study helps to demonstrate how the use of fluoride varnish in the hands of lay professionals provides a simple and safe caries-preventive therapy that can be utilized as a public health intervention through different providers when governmental organizations recognize that the benefits can far outweigh minimal risks.

\section{Acknowledgments}

The authors would like to thank the numerous faculty members, students and staff from the NYUCD who worked tirelessly through long hours in the heat, rain and damp. We would also like to thank the teachers, principals, parents, and the people and Ministries of Grenada for their support, assistance and participation in the Smile Grenada program. This would not have been possible without the support of the NYUCD and our sponsors Colgate Palmolive, GC America, Henry Schein Cares and Columbia Den- toform. Special thanks needs to be offered to Ms. Rachel Hill whose coordination and persistence made this happen and Ms. Gracelyn Harris, Ms. Jill Fernandez, Ms. Alison Kurtz, Ms. Danielle Becker, Mr. Christopher Tung and Ms. Lisa Haystrand for their coordination and persistence.

\section{Author Contributions}

All authors listed participated actively in the preparation of the manuscript and intervention/research project.

\section{Disclosure Statement}

Mark S. Wolff declares that he is a compensated consultant and researcher for the Colgate Palmolive Company. This project was funded in part by the generous support of the Colgate Palmolive Company, Henry Schein Cares, GC American and NYUCD.

\section{References}

Agouropoulos A, Twetman S, Pandis N, Kavvadia $\mathrm{K}$, Papagiannoulis L: Caries-preventive effectiveness of fluoride varnish as adjunct to oral health promotion and supervised tooth brushing in preschool children: A doubleblind randomized controlled trial. J Dent 2014;42:1277-1283.

Ahovuo-Saloranta A, Hiiri A, Nordblad A, Makela M, Worthington HV: Pit and fissure sealants for preventing dental decay in the permanent teeth of children and adolescents. Cochrane Database Syst Rev 2008;4:CD001830.

Antonson SA, Wanuck J, Antonson DE: Surface protection for newly erupting first molars. Compend Contin Educ Dent 2006;27:46-52.

Armfield JM: Community effectiveness of public water fluoridation in reducing children's dental disease. Public Health Rep 2010;125:655-664.

Baez R: Salt Fluoridation Program in Grenada, West Indies. Washington, Pan American Health Organization, Office of Caribbean Program Coordination, Barbados, World Health Organization Collaborating Centre in Oral Health, University of Texas Health Sciences Center at San Antonio, 2001.

Brown LJ, Wall TP, Lazar V: Trends in total caries experience: Permanent and primary teeth. J Am Dent Assoc 2000;131:223-231.

Brunelle JA, Carlos JP: Recent trends in dental caries in US Children and the effect of water fluoridation. J Dent Res 1990;69::723-727; discussion 820-823.

Estupiñán-Day S: Promoting Oral Health: Progress and Success, 1980-2000. Washington, Pan American Health Organization, 2005. publications.paho.org/english/SP_615_Section_3.pdf.
Flanders RA: Grenada 1984: health care 3 months after the US intervention. J Am Dent Assoc 1984;109:939-941.

Gooch BF, Griffin SO, Gray SK, Kohn WG, Rozier RG, Siegal M, Fontana M, Brunson D, Carter N, Curtis DK, Donly KJ, Haering H, Hill LF, Hinson HP, Kumar J, Lampiris L, Mallatt M, Meyer DM, Miller WR, Sanzi-Schaedel SM, Simonsen R, Truman BI, Zero DT; Centers for Disease Control and Prevention: Preventing dental caries through school-based sealant programs: updated recommendations and reviews of evidence. J Am Dent Assoc 2009; 140:1356-1365.

Government of Granada Web Portal: Grenada Fast Facts. 2014. http://www.gov.gd/about_ grenada.html.

Griffin SO, Oong E, Kohn W, Vidakovic B, et al: The effectiveness of sealants in managing caries lesions. J Dent Res 2008;87:169-174.

Hiiri A, Ahovuo-Saloranta A, Nordblad A, Makela M: Pit and fissure sealants versus fluoride varnishes for preventing dental decay in children and adolescents. Cochrane Database Syst Rev 2010;3:CD003067.

Johnson NW, Lalloo R, Kroon J, Fernando S, Tut $\mathrm{O}$ : Effectiveness of water fluoridation in caries reduction in a remote indigenous community in Far North Queensland. Aust Dent J 2014; 59:366-371.

Marinho VC, Worthington HV, Walsh T, Clarkson JE: Fluoride varnishes for preventing dental caries in children and adolescents. Cochrane Database Syst Rev 2013;7:CD002279.

Mejare I, Mjor IA: Glass ionomer and resin-based fissure sealants: a clinical study. Scand J Dent Res 1990;98:345-350.
Milsom KM, Blinkhorn AS, Walsh T, Worthington HV, Kearney-Mitchell P, Whitehead H, Tickle M: A cluster-randomized controlled trial: fluoride varnish in school children. J Dent Res 2011;90:1306-1311.

Newbrun E: Effectiveness of water fluoridation. J Public Health Dent 1989;49:279-289.

Poulsen S, Beiruti N, Sadat N: A comparison of retention and the effect on caries of fissure sealing with a glass-ionomer and a resinbased sealant. Community Dent Oral Epidemiol 2001;29:298-301.

Rugg-Gunn AJ, Do L: Effectiveness of water fluoridation in caries prevention. Community Dent Oral Epidemiol 2012;40(suppl 2):55-64.

Smales RJ, Wong KC: 2-year clinical performance of a resin-modified glass ionomer sealant. Am J Dent 1999;12:59-61.

Twetman S, Axelsson S, Dahlgren H, Holm AK, Kallestal C, Lagerlof F, Lingstrom P, Mejare I, Nordenram G, Norlund A, Petersson LG, Soder B: Caries-preventive effect of fluoride toothpaste: a systematic review. Acta Odontol Scand 2003;61:347-355.

Weintraub JA, Ramos-Gomez F, Jue B, Shain S, Hoover CI, Featherstone JD, Gansky SA: Fluoride varnish efficacy in preventing early childhood caries. J Dent Res 2006;85:172176.

World Health Organization: Health in the Americas: 2007. Washington, Pan American Health Organization, World Health Organization, 2007.

World Health Organization: Oral Health Surveys: Basic Methods, ed 4. Geneva, World Health Organization, 1997. 